\title{
Urology: Scrotal Pain
}

John E. David, MD, Department of Internal Medicine, Marshfield Clinic, Marshfield, Wisconsin

Steven H. Yale, MD, Department of Internal Medicine, Marshfield Clinic, Marshfield, Wisconsin

I. Lee Goldman, MD, Department of Urology, Marshfield Clinic, Marshfield, Wisconsin

\section{REPRINT REQUESTS:}

Steven Yale, MD

Department of Internal Medicine

Marshfield Clinic

1000 North Oak Avenue

Marshfield, WI 54449

Telephone: $715-387-5436$

Fax: 715-389-3808

Email: yale.steven@marshfieldclinic.org

\section{KEYWORDS:}

Scrotal pain; Testicular torsion; Epididymitis; Urethritis; Cremasteric reflex; Fournier's gangrene; Process vaginalis, Sign of Bryant
Clinical Medicine \& Research

Volume 1, Number 2: 159-160

(0)2003 Clinical Medicine \& Research

www.mfldclin.edu/clinmedres
What are the three most important details to obtain from the history in patients who present with acute scrotal pain?

The three most important details to obtain include the patient's age, the description of the pain and sexual history. The history in conjunction with the physical examination can provide important clues as to the exact cause for acute scrotal pain. Age is a key factor since many conditions responsible for acute scrotum commonly occur in certain age groups. For example, testicular torsion has a peak incidence in the neonatal and postpuberal stages. In contrast, torsion of the appendices (testis and epididymis) most often occurs during early adolescence. Epididymitis occurring in prepuberal boys may be associated with abnormalities involving the genitourinary tract. In adolescent and young adults, most cases are secondary to sexual transmitted diseases.

The description of the pain can provide important clues to the underlying etiology. Conditions affecting the scrotum can secondarily cause referred pain to the abdomen and inguinal canal. Conversely, an acute scrotal presentation may be part of the spectrum of a disease process occurring from within the abdomen. Torsion of the appendiceal testes presents with the sudden onset of scrotal pain and thus is clinically indistinguishable from testicular torsion. In both conditions, patients may recall having similar episodes of testicular pain in the past that spontaneously resolved. Epididymitis presents with a gradual onset of unilateral scrotal pain that increases in severity and extends over a period of hours to days. If concomitant urethritis is present, patients will also give a history of dysuria.

\section{What is the most sensitive physical finding for testicular torsion?}

The cremasteric reflex is the most sensitive physical finding for testicular torsion. The specificity of this reflex is variable in different age groups. In suspected testicular torsion and/or scrotal pain, a complete abdominal, genitourinary, and prostate examination is important. Scrotal examination should include inspection, palpation and in selected case transillumination. The examination should also include the elicitation of the cremasteric reflex. This reflex is elicited by pinching or lightly stroking from caudally to cranially the superior-medial aspect of the thigh. The presence of the reflex is indicated by elevation of the ipsilateral testicle. In patients with testicular torsion, this reflex is absent. 


\section{Which causes for acute nontraumatic scrotal pain require emergent intervention?}

The most important nontraumatic conditions presenting with acute scrotal pain and requiring prompt, accurate diagnosis and emergent intervention are: ruptured or dissecting abdominal aortic aneurysm, peritonitis, strangulated inguinal hernia, Fournier's gangrene, and testicular torsion.

The first three conditions may secondarily involve the scrotum. This depends on whether a patent process vaginalis is present. The process vaginalis is a direct result of the migration of the testes from its abdominal location to the scrotum. Failure of the process vaginalis to close leads to a direct communication between the abdominal cavity and the scrotum. Thus, pus, blood or bowel can travel into the scrotum causing acute pain. Blood within the scrotum may lead to an eccymotic appearance referred to as "the blue scrotum sign of Bryant." In the appropriate clinical setting, this sign may provide a clue to the diagnosis of a ruptured abdominal aortic aneurysm as originally described by Dr. John Henry Bryant at the turn of the century.

Fournier's gangrene is a necrotizing polymicrobial infection involving multiple facial planes of the perineum and anterior abdominal wall (table 1). Multiple risk factors have been associated with this condition (table 2). Treatment should be directed toward prompt fluid resuscitation and hemodynamic stabilization, broad-spectrum antibiotics, early surgical drainage and debridement. Early hyperbaric oxygen therapy has been shown to provide a significantly higher survival advantage.

Testicular torsion is a result of twisting of the spermatic cord leading to testicular ischemia. Prompt diagnosis is essential since testicular salvage rate depends upon the duration of the ischemia. A $100 \%$ success rate was reported in the first 6 hour, falling to $75 \%$ for 24 hours or more since the onset of the symptoms. Torsion of the appendix testis is distinguished by the presence of a small painful, firm paratesticular nodule located at the superior pole of the testis.

Inspection of the scrotum may reveal a "blue-dot" sign, which represents the infarcted appendage as seen through the scrotal skin. Differentiating this condition from torsion of the appendix testis is important since testicular torsion is a surgical emergency; while torsion of the appendix is treated with conservative measures include rest, testicular elevation and analgesics.

Table 1. Microbes typically seen in Fournier's Gangrene.

Anaerobic streptococci

Proteus spp.

Escherichia Coli (E. coli)

Staphylococcus aureus (S. aureus)

Beta-hemolytic streptococci

Various anaerobes.

Pseudomonas spp.
Table 2. Risk factors for Fournier's Gangrene.

Diabetes mellitus

Ethanol abuse

Local trauma or instrumentation to the perineum

Paraphimosis

Extravasations of urine periurethrally or through a cutaneous fistula

Urethral stricture caused by sexually transmitted diseases

Circumcision and hernioplasty

\section{FURTHER READING}

Hollabaugh RS Jr, Dmochowski RR, Hickerson WL, Cox CE. Fournier's gangrene: therapeutic impact of hyperbaric oxygen. Plast Reconstr Surg 1998;101:94-100.

Marcozzi D, Suner S. The nontraumatic acute scrotum. Emerg Med Clin North Am 2001;19:547-568.

Rampaul MS, Hosking SW. Testicular torsion: Most delays occur outside hospital. Ann R Coll Surg Engl 1998;80:169-172.

Ratzan RM, Donaldson MC, Foster JH, Walzak MP. The blue scrotum sign of Bryant: a diagnostic clue to ruptured abdominal aortic aneurysm. J Emerg Med 1987;5:323-329.

Siegel MJ. The acute scrotum. Radiol Clin North Am 1997;35:959976. 